\title{
Direitos sociais às margens: \\ um debate sobre políticas \\ públicas de educação \\ e saúde em dois estudos de caso de Saint-Denis
}

\author{
Miranda Zamberlan Nedel, \\ Ricardo de Lima Jurca, \\ Cibele Saliba Rizek, \\ Miguel Antonio Buzzar*
}

\begin{abstract}
Resumo A comuna de Saint-Denis (região metropolitana parisiense, França) congrega em um mesmo campo de pesquisa: as representações arquitetônicas e urbanísticas do território periférico, a vinculação entre pobreza e políticas sociais e as formas de precarização do trabalho, observadas sob a perspectiva da racionalidade neoliberal nos campos da educação e da saúde. A hipótese do trabalho é de que o avanço neoliberal é empiricamente verificável nas transformações gerenciais e privatistas das políticas de educação e saúde em dois estudos de caso de Saint-Denis, o Lycée Sugere o Hospital Delafontaine. Utilizando-se de incursões etnográficas, entrevistas semiestruturadas e conversas informais, aborda-se igualmente o cotidiano do trabalho dos profissionais do "chão de fábrica" destas duas instituições.
\end{abstract}

Palavras-chave: neoliberalismo, políticas sociais, territórios periféricos.

Los derechos sociales en los márgenes: un debate sobre políticas públicas de educación y salud en dos estudios de caso de Saint-Denis

\begin{abstract}
Resumen La comuna de Saint-Denis (área metropolitana de París, Francia) reúne en un mismo campo de investigación: las representaciones arquitectónicas y urbanas del territorio periférico, el vínculo entre la pobreza y las políticas sociales y las formas de precarización laboral, observadas desde la perspectiva de la racionalidad neoliberal en los ámbitos de la educación y la salud. La hipótesis del trabajo es que el avance neoliberal es empíricamente verificable en las transformaciones gerenciales y privatizadoras de las políticas educativas y sanitarias en dos estudios de caso de Saint-Denis, el Liceo Suger y el Hospital Delafontaine. Mediante incursiones etnográficas, entrevistas semiestructuradas y conversaciones informales, se aborda también el trabajo diario de los profesionales del "piso de fábrica" de estas dos instituciones.
\end{abstract}

Palabras clave: neoliberalismo, políticas sociales, territorios periféricos.
Social rights at the margins: a debate on education and health public policies in two case studies from Saint-Denis

\begin{abstract}
The commune of Saint-Denis (Paris metropolitan area, France) brings together in the same field of research: the architectural and urbanistic representations of the peripheral territory, the link between poverty and social policies, and the forms of labor precarization, observed from the perspective of neoliberal rationality in the fields of education and health. The hypothesis of the paper is that the neoliberal advance is empirically verifiable in the managerial and privatized transformations of education and health policies in two case studies from Saint-Denis, the Lycée Suger and the Delafontaine Hospital. Using ethnographic incursions, semi-structured interviews and informal conversations, the daily work of professionals on the "shop floor" of these two institutions is also addressed.
\end{abstract}

Keywords: neoliberalism, social policies, peripheral territories. 


\section{território, os estudos de caso e as entradas em campo}

Face às inúmeras manifestações sociais, à mais longa greve da história da França ${ }^{1}$ e à crise sanitária decorrente da pandemia do Covid-19, o debate a respeito dos direitos sociais está longe de ser findo. Em tempos de aparente integração por causas comuns, há de se ressaltar, entretanto, a dimensão territorial diferenciada de garantia desses direitos. O estudo empírico de uma periferia de Saint-Denis, Nordeste de Paris, região metropolitana parisiense (Île-de-France), parafraseando Roberto Schwarz (1992) ajuda a compreender dialeticamente o(s) centro(s), não apenas o centro parisiense, mas igualmente o cerne de políticas de conteúdo neoliberal que vêm sendo adotadas pelos países do Norte e têm nas periferias - internas, mas também externas, sobretudo dos países do Sul global - territórios privilegiados de experimentação social.

A definição da comuna de Saint-Denis, do departamento de Seine-Saint-Denis, para a realização das incursões em campo, decorre de suas características sociais: segundo dados do Institut National de la Statistique et des Études Économiques(INSEE), a comuna apresenta expressivo crescimento populacional e elevadas taxa de desemprego (superior a $22 \%$ em 2017) e de pobreza (37\% em 2018). Ademais, destaca-se a forte presença de migrantes no departamento de Seine-Saint-Denis, cerca de 30\% da população em 2017 (LINTERNAUTE, 2017, On-line). Somam-se às características populacionais e sociais os inúmeros projetos urbanos em curso em Saint-Denis, associados às obras do projeto de interligação do transporte público metropolitano da grand couronne de Paris, o Grand Paris Express, o projeto urbano de Métropole du Grand Paris e o

* Miranda Zamberlan Nedel é Arquiteta e Urbanista, Doutoranda no Programa de Pós-Graduação do Instituto de Arquitetura e Urbanismo da Universidade de São Paulo, ORCID <https://orcid. org/0000-0001-8132-3634>. Ricardo de Lima Jurca é Sociólogo, Pesquisador de Pós-Doutorado do Instituto de Arquitetura e Urbanismo da Universidade São Paulo e pesquisador do grupo de pesquisa Social Activities, Gender, Markets And Mobilities from Bellow (Latin America), ORCID <https://orcid. org/0000-0003-3226-4839>. Cibele Saliba Rizek é Socióloga, Professora do Instituto de Arquitetura e Urbanismo da Universidade de São Paulo, ORCID <https://orcid.org/0000-0002-7871-5730>. Miguel Antonio Buzzar é Arquiteto e Urbanista, Professora do Instituto de Arquitetura e Urbanismo da Universidade de São Paulo, ORCID <https://orcid.org/00000001-6251-0338>. conjunto de intervenções vinculadas aos Jogos Olímpicos e Paraolímpicos de 2024.

Este artigo é resultado do mapeamento das formas de penetração da racionalidade neoliberal e de lógicas empresariais nas políticas públicas de saúde e educação em dois estudos de caso localizados na comuna de Saint-Denis, o Hospital Delafontaine e o Lycée Suger, respectivamente edifícios públicos de saúde e de educação. Ao comparar dois casos contrastantes, Educação e Saúde, pretendemos trabalhar especificamente sobre as dinâmicas da institucionalização tanto da situação de emprego quanto dos direitos e prerrogativas sociais sob a racionalidade neoliberal ${ }^{2}$. Analisar a penetração de discursos e interesses dessa ordem em equipamentos públicos escolares e de saúde é, portanto, analisar fronteiras de uma transformação mercadológica, privatista e/ou empresarial que altera profundamente e, em última instância, coloca em xeque os direitos sociais à saúde e educação, por meio de políticas, programas e dos próprios agentes relacionados à concretização de tais direitos.

Ainda a respeito de Saint-Denis, destaca-se que a comuna faz parte do histórico cinturão vermelho de Paris, sendo que o final do século XX foi marcado pela transição gradual da imagem da "banlieue rouge" para a imagem do "93"3. Estas duas figuras tornaram-se vetor de identidade e unidade para este departamento e símbolo das tensões que o animam (BEHAR; LOISEL; RIO, 2016), capazes de articular 
1 Greve contra a reforma da previdência, iniciada em 5 de dezembro de 2019 e que se estendeu até 20 de fevereiro de 2020.

2 Laval e Dardot (2016) definem o neoliberalismo como uma racionalidade que é também dispositivo de subjetivação, que tem na empresa o ideal normativo por excelência (DARDOT; LAVAL, 2016). Esta análise referencia-se em Foucault, em especial em "Nascimento da biopolítica" (2008), obra na qual compreendem-se as "políticas neoliberais" como pautadas por esta racionalidade ancorada nos princípios do mercado, da concorrência, do modelo de sociedade empresarial e da individualização da política social, enfim, uma "política social privatizada" (FOUCAULT, 2008, p. 199).

30 departamento de Seine-SaintDenis é identificado pelo número departamental 93.

4 Vide vídeo em Métropole Grand Paris (2016, On-line).

Figura 1: Imagem aérea do território de entorno aos estudos de caso. Fonte: Elaborado pelos autores (2020) a partir de imagem do Google Earth. o funcionamento socioeconômico do território com o seu posicionamento político. No entanto, esta articulação é regularmente posta à prova, devido à intensidade das mudanças em curso neste território.

É importante ressaltar as dinâmicas migratórias que a história urbana desta região de Saint-Denis congrega e que têm na Cité Franc Moisin, imenso conjunto edificado de habitação social, uma importante expressão. Considerada uma das mais importantes favelas da França nos anos 1970, que abrigava mais de 5000 pessoas, foi resultante de importante afluxo de imigrantes algerianos (no final da Segunda Guerra Mundial) e portugueses (sobretudo após os anos 1960, quando da extinção de outra ocupação de forte presença portuguesa). Após um severo incêndio em 1970, que resultou em mais de 600 mortos, foi palco da construção do conjunto de mais de 1800 unidades habitacionais sociais (Habitation à Loyer Modéré-HLM), inaugurado em 1974 (SEINESAINT-DENIS TOURISME, [200-], On-line).

Tanto a escola quanto o hospital analisados, que distam cerca de um quilômetro e meio (se percorrido a pé), localizam-se nos entornos do Stade de France, às margens do Canal de Saint-Denis, região que tem sido alvo de importantes intervenções urbanas, sobretudo nas proximidades da Place de la Porte de Paris (Figura 1). Esta região foi, nos últimos anos, intensamente transformada por parte de um amplo plano de reurbanização, o "Projet de réaménagement de la Porte de Paris à Saint-Denis", que integra o Grande Projeto Urbano de Plaine Commune e que, por sua vez, faz parte da Métropole du Grand Paris, agrupamento criado em 2014, envolvendo inúmeros planos estratégicos, projetos e obras urbanísticas, que buscam concretizar a imagem da região metropolitana parisiense como metrópole mundial inovadora e atrativa, enfim, uma metrópole do "futuro" ${ }^{4}$. As obras em preparação aos Jogos Olímpicos vinculam-se a este projeto metropolitano.

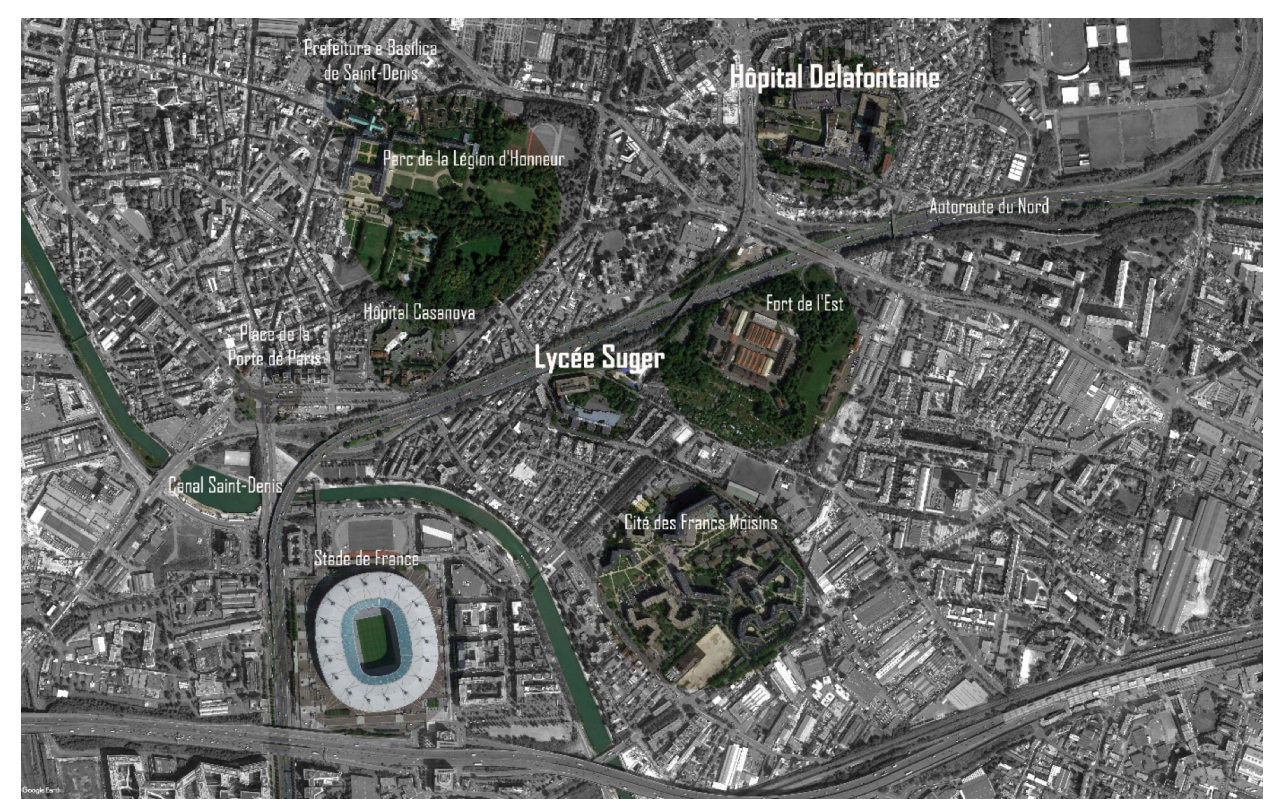


5 Para a realização do artigo contou-se com entrevistas com três funcionários de administrações escolares (um coordenador e dois diretores, respectivamente do Lycée Suger e do Collège Dora Maar) e conversas informais com três funcionários (dois enfermeiros e uma técnica de enfermagem) do Hospital, uma professora e cerca de 10 funcionários da escola. Por questões éticas os nomes dos entrevistados foram omitidos e substituídos por E1, E2, E3, E4 etc. As entrevistas foram realizadas com concordância formal dos participantes ao Termo de Consentimento Livre e Esclarecido (TCLE) apresentado pela pesquisadora Miranda Zamberlan Nedel, a qual obteve autorização para a realização da pesquisa através do Parecer $n^{\circ} 3.193 .988$ e Certificado de Apresentação para Apreciação Ética (CAAE) $n^{\circ}:$ 04437118.6.0000.5390, aprovados junto ao Comitê de Ética em Pesquisa da Escola de Artes, Ciências e Humanidades da Universidade de São Paulo EACH/USP. A emenda relativa ao trabalho de campo realizado na França foi aprovada em Parecer no: 3.843.575.

${ }^{6}$ As incursões foram realizadas como pesquisa de campo de estágio de mestrado realizado junto ao Laboratoire Sophiapol Unité De Recherche en Sociologie, Philosophie et Anthropologie Politiques de l'Université Paris Nanterre. $\mathrm{O}$ estágio integrou $\mathrm{O}$ Mestrado em Arquitetura e Urbanismo concluído em 2020 pela pesquisadora Miranda Zamberlan Nedel, no Instituto de Arquitetura e Urbanismo da Universidade de São Paulo, com apoio da Coordenação de Aperfeiçoamento de Pessoal de Nível Superior - Brasil (CAPES), com o título "Educação em disputa: Tessituras comuns entre escolas públicas periféricas da Região Metropolitana de São Paulo e de île-de-France frente aos avanços neoliberais".
Justamente para tentar dar conta da indefinição e redefinição permanente das fronteiras entre os dois estudos de caso, em meio a um contexto urbano em transformação, a preocupação foi colocar em relevo a consciência das mesmas por parte dos indivíduos, por meio da análise dos dados etnográficos coletados durante as pesquisas de campo. As incursões em campo ocorreram entre os meses de outubro e dezembro de 2019, entretanto, as presentes análises são atravessadas por dois eventos de larga duração, já citados, que demarcam espécies de balizas temporais do trabalho: a greve contra a reforma da previdência e a pandemia de covid-19, sendo que ambos se entremeiam ao debate das transformações neoliberais nos campos da saúde e educação pública no território definido. A greve, que contou com forte mobilização dos sindicatos dos quadros da saúde e da educação, expôs a crua realidade do exercício profissional, em meio a processos, em curso, de corrosão do sentido público de tais serviços. A pandemia, por sua vez, escancarou a sobrecarga e o esgotamento do sistema público de saúde, assim como os limites do sistema público de ensino, obrigado a percorrer caminhos emergenciais na trilha da educação a distância.

Embora na contramão das políticas neoliberais, a pandemia permite problematizar os sentidos de "serviço público" a partir da contribuição de Léon Duguit, que o define enquanto obrigação legal dos governantes para com as necessidades da sociedade, ou seja, à "serviço do público" (LAVAL; DARDOT, 2020, On-line). Essa concepção de serviço público carece de debate no crítico contexto atual, em que a orientação hegemônica à serviço do mercado depara-se com uma emergência de saúde pública mundial, com impacto imensurável também à educação.

A hipótese dos autores é de que a racionalidade neoliberal é empiricamente verificável nas transformações gerenciais e privatistas da educação e da saúde nos estudos de caso de Saint-Denis. Estas, por sua vez, vinculam-se às reformas trabalhistas e ao processo de precarização do trabalho. Assim, o "chão de fábrica" da escola e do hospital - as competências de "ser" e "fazer" desses trabalhadores - configura importante objeto de análise, pois repercute o duplo movimento de exigência de maximização da performance e precarização do trabalho ao mesmo tempo em que tensiona as políticas de educação ao demandar um trabalhador subjetivado ao mercado de trabalho flexível contemporâneo.

O presente trabalho busca enunciar as modulações das políticas e programas sociais como terrenos de disputa. Tendo como método a pesquisa de campo e utilizandose de incursões etnográficas, entrevistas semiestruturadas e conversas informais ${ }^{5}$, buscou-se apreender um mesmo universo periférico tão diverso.

\section{Entre direito e mercadoria: manifestações neoliberais em uma escola de Saint-Denis}

O Lycée Suger ${ }^{6}$ foi definido para análise do avanço neoliberal na educação e suas reverberações no cotidiano escolar: no campo do trabalho docente, na profissionalização das formações e nas diferenciações socioterritoriais via escola. A definição do Lycée Suger decorre de sua excepcionalidade arquitetônica e educacional. Trata-se de uma instituição pública que agrega formações de nível secundário geral (filières generale), tecnológicas (filières technologiques), profissionais (formation professionnelle) sobretudo para o setor terciário, em venda, em comércio, em gestão de administrações 


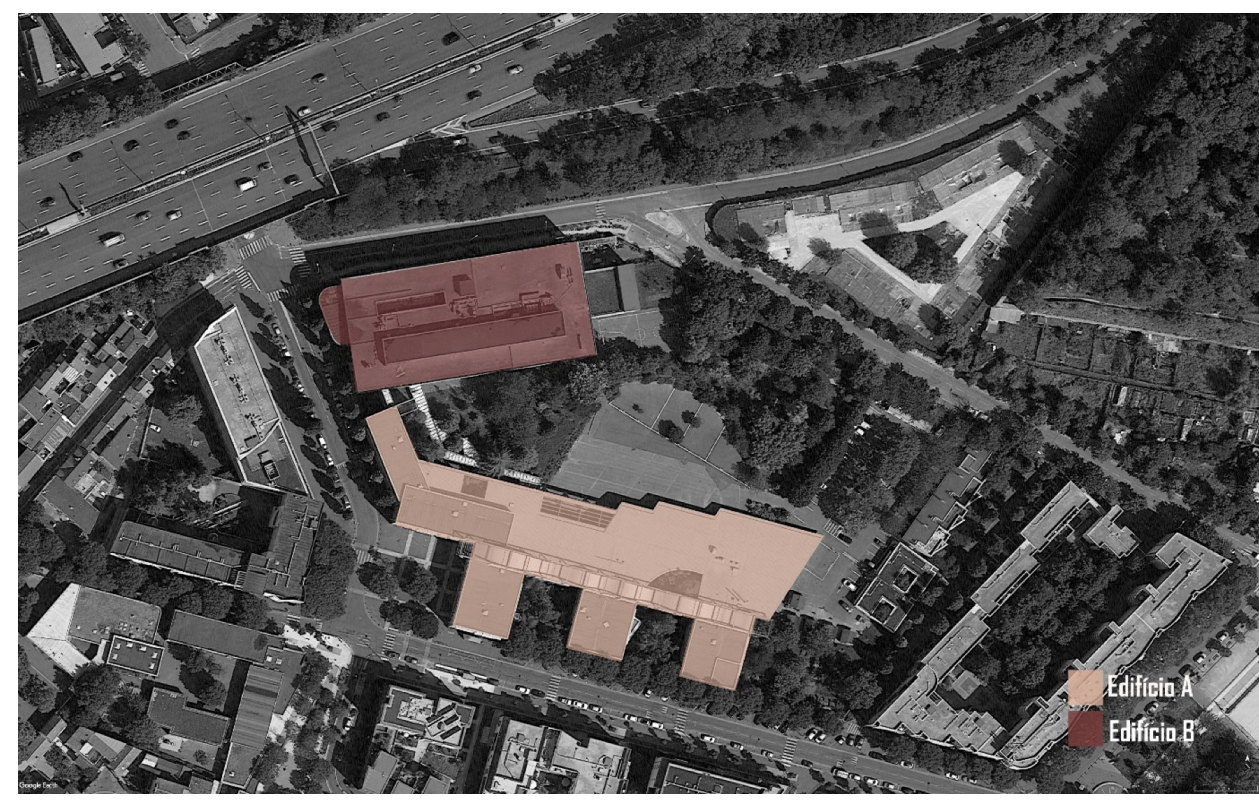

Figura 2: Imagem aérea do Lycée Suger, com identificação dos dois edifícios. Fonte: Elaborado pelos autores (2020) a partir de imagem do Google Earth.

\footnotetext{
7 Plataforma digital nacional de pré-inscrição no primeiro ano de ensino superior na França, lançada em janeiro de 2018, por parte do Ministère de l'Éducation Nationale et de la Jeunesse e do Ministère de l'Enseignement Supérieur, de la Recherche et de I'Innovation.

8 Destaca-se a vinculação dessa rotulação com a caracterização das comunas agrupadas em Plaine Commune, da qual Saint-Denis faz parte, como "Territoire de la culture et de la création" (Território da cultura e da criação) na Métropole du Grand Paris, nessa construção imagética de uma metrópole mundial inovadora.
}

assim como em fotografia, BAC Photo -, formação em nível superior em audiovisual ( Brevet de technicien supérieur - BTS audiovisuel), além de formação continuada profissional de jovens e adultos realizada pela rede GRETA (dispositivo da educação nacional), em paisagismo e jardinagem. Considerando todas as formações, o lycée escolariza cerca de 1200 alunos, realizando seleções para o BTS (por meio da plataforma Parcoursup ${ }^{7}$ ) e para o BAC Photo (por meio de entrevista), devido à grande demanda e vagas insuficientes nestas duas formações.

O Lycée Suger é uma instituição existente desde 1994, que em 2011, após ter sido rotulado como "lycée des métiers de l'image et du son"8 (LYCÉE SUGER, [201-], On-line), foi acrescida de uma nova edificação (edifício B), voltada às formações em Audiovisual e Fotografia. O projeto do novo edifício, agregado à edificação $A$ preexistente (Figura 2), foi projetado pelo escritório Jacques Ripault Architecture e atendeu a um programa técnico bastante específico, o qual inclui estúdio de som, sala de projeção, sala de controle, centro de fotos e processamento, laboratório de impressão, para além das salas de aula do ensino geral. O grande bloco edificado destaca-se no entorno urbano pelo formato orgânico do volume do auditório revestido em aço corten (Figura 3), assim como pela utilização dos brises soleils metálicos e de uma extensa fachada cega de três pavimentos pintada em preto, uma referência, segundo o discurso arquitetônico, à caixa preta da fotografia (vinculada à formação oferecida no $L y c e ́ e$ e) ès pinturas de Soulages. $O$ apelo imagético, a grande depuração das fachadas e os materiais utilizados neste edifício parecem manifestar a exploração por parte da arquitetura escolar contemporânea da construção imagética do lugar com forte sentido de empreendedorismo urbano (HARVEY, 2005) -, que destoa do entorno, embora relacionando-se às citadas transformações em curso no território, ligadas aos megaeventos e grandes projetos urbanos metropolitanos. 
Figura 3: Fachada do anfiteatro do Lycée Suger. Fonte: Autores (2019).

9 "[...] Le fait que l'école ne se contente pas de reproduire les différenciations urbaines, mais est ele-même productrice de différenciations à travers son fonctionnement interne" (VAN ZANTEN, 2001, Introd., n.p.).

10 Do ponto de vista da Educação Nacional, a França é dividida administrativamente em Académies, sendo a região metropolitana de Paris dividida nas academias de Créteil, Paris e Versailles.

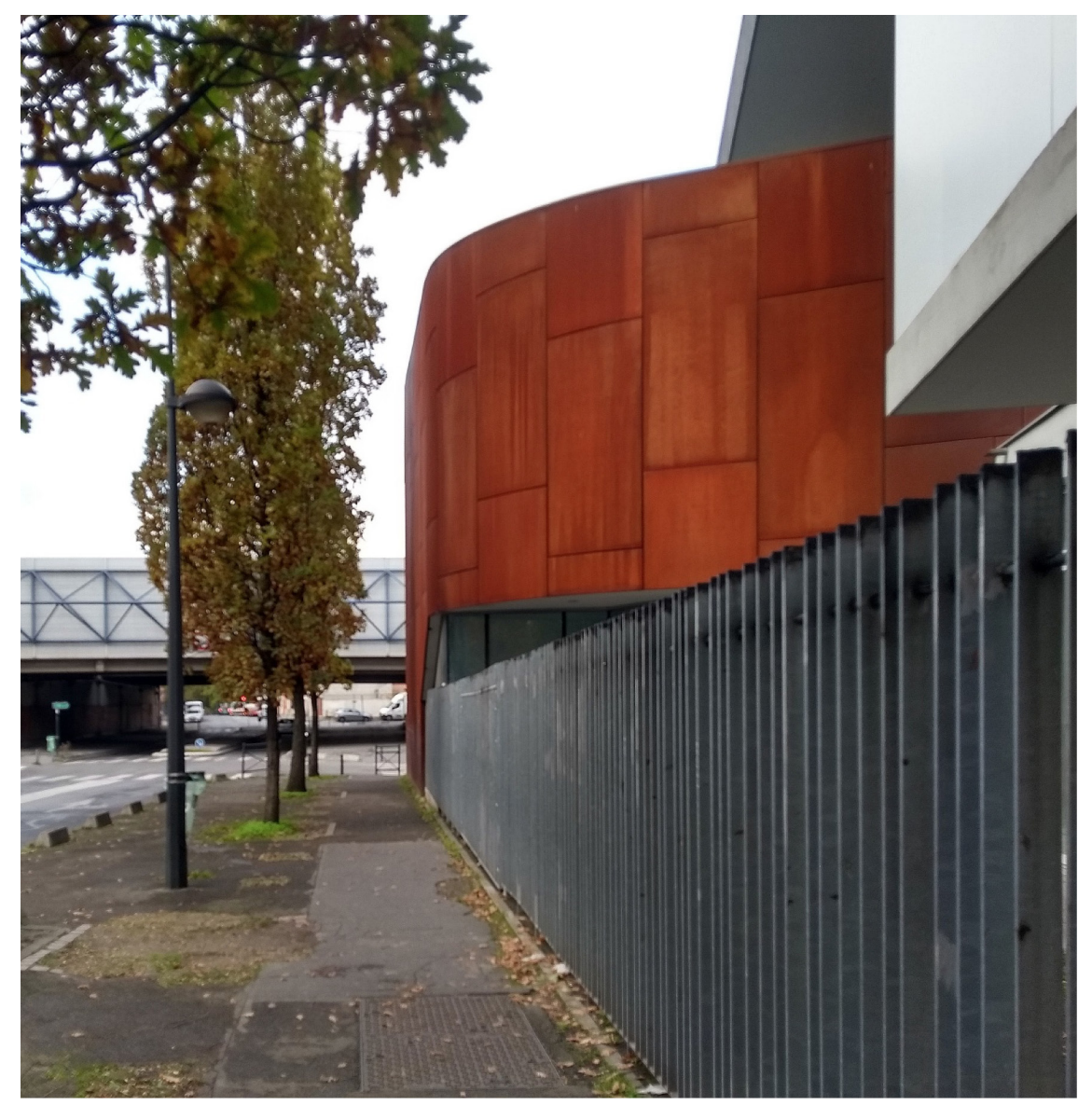

Por meio deste estudo de caso, serão debatidas, a seguir, modulações territoriais do avanço neoliberal na educação, a partir do exercício profissional docente e da lógica de profissionalização da educação.

\section{A escola e o território}

Segundo Van Zanten (2001), compreende-se a dimensão territorial associada à instituição escolar, pois a escola "não se contenta em reproduzir as diferenciações urbanas, mas é ela mesma produtora de diferenciações através de seu funcionamento interno" (Introd., n.p., tradução nossa ${ }^{9}$ ). O conceito de "escola periférica" ("école périphérique") da autora agrega, pois, um sentido de desigualdade socioterritorial, a partir da compreensão da existência de diferenciações sociais das populações escolares, que se traduzem em termos espaciais.

Observou-se, no Lycée Suger, que estas diferenciações territoriais perpassam o próprio trabalho docente. Como um funcionário afirmou, o Lycée Suger, assim como outras escolas periféricas da Academia ${ }^{10}$ de Créteil, concentram, em geral, os professores mais jovens, no início de suas carreiras e menos qualificados, devido ao sistema de pontos que determina em qual Academia cada professor lecionará, após ter sido aprovado em concurso nacional. 
Figura 4: Vão central do edifício B do Lycée Suger. Fonte: Autores (2019).
Relacionado a isto, Christian Laval, Francis Vergne, Pierre Clément e Guy Dreux em "La nouvelle école capitaliste"(2012) evidenciam que as desigualdades dos capitais culturais se somam às desigualdades das condições de ensino e atravessam as relações de ensinoaprendizagem nestas escolas periféricas, demandando uma estratégia de adaptação das atividades docente ao contexto social. Como o diretor de outro estabelecimento escolar periférico de Saint-Denis, o Collège Dora Maar, ressaltou, dentre os professores destas escolas ressoa a percepção de realizarem distintos "métiers", em comparação a colegas de escolas mais centrais, visto que o cotidiano escolar apresentava questões e preocupações de outra ordem, como as ocorrências de violências, conflitos e focos de incêndio no Lycée Suger (PERRIER, 2016, On-line; SAINT-DENIS..., 2017, On-line).

Uma jovem professora do lycée relatou, informalmente, a clivagem entre alunos e professores de formações distintas, principalmente entre as formações gerais/ profissionais e o BTS, mais valorizado e que acaba por se destinar a alunos de outros contextos urbanos (de toda a região e mesmo de outras regiões francesas). A clivagem se dava também espacialmente, entre salas de professores e edifícios distintos: o novo edifício, equipado com modernos equipamentos de audiovisual, com volumes coloridos destacados e passarelas metálicas que se entrecruzam, era utilizado sobretudo pelos

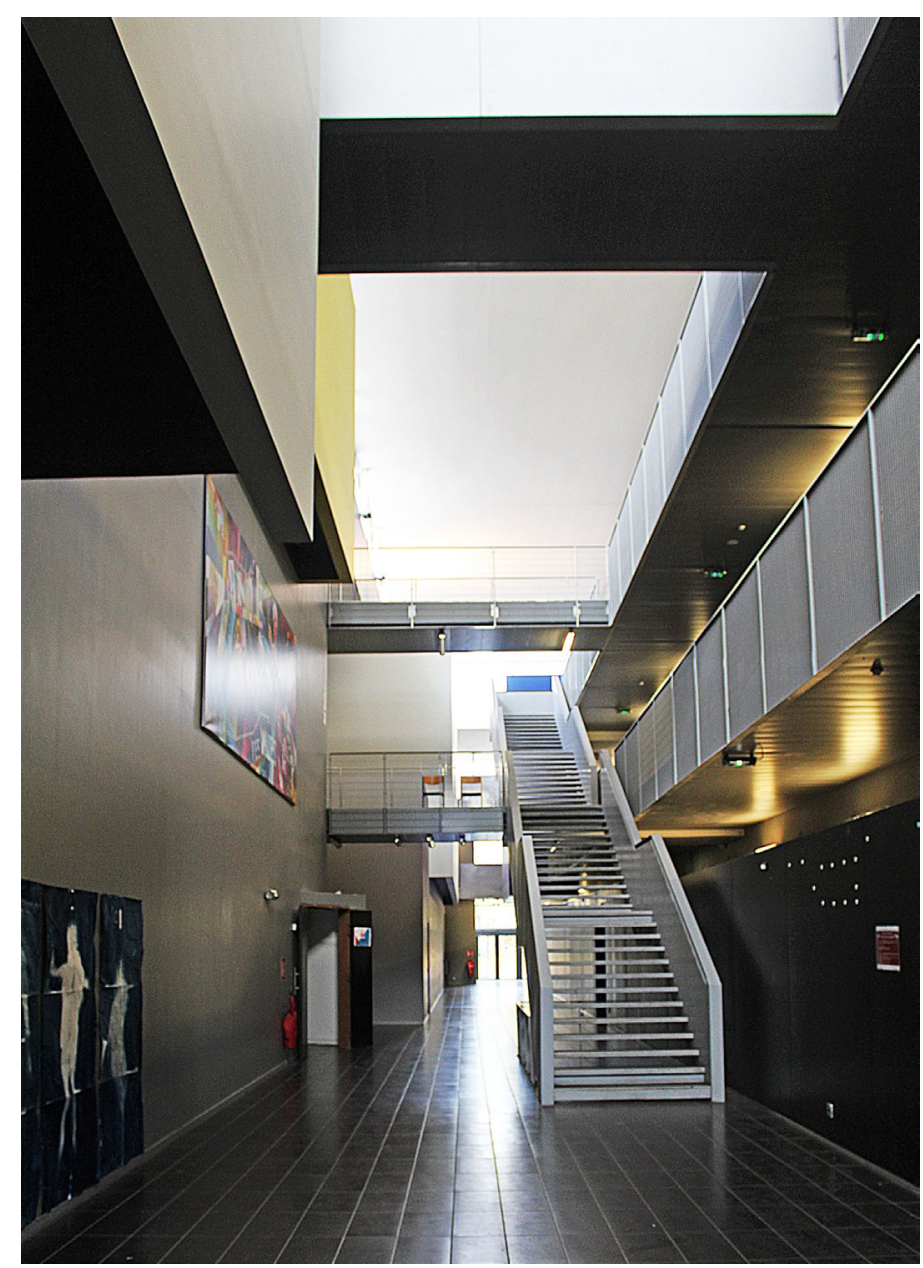


11 "[...] / 'poches de difficultés', d' 'établissement sensibles' "( LAVAL et al., 2012, Cap.04, n.p.).

12 "[...] un puissant levier de reproduction sociale [...]» (LAVAL et al., 2012, Cap.04, n.p.).
13 "[...] /"employabilité" est le principe et l'objectif de la normalisation de l'école, de son organisation et de sa pédagogie" (LAVAL et al., 2012, Apres., n.p.).

14 " C'est un nouveau régime salarial qui s'instaure et qui impose sa norme au monde de l'éducation: former des individus adaptables et des personnalités fluides" (LAVAL et al., 2012, Introd., n.p.).

15 Entrevista realizada no dia 13 de novembro de 2019, na sala do entrevistado no Lycée.
16 "L'apprentissage se veut justement un tremplin vers le monde de l'entreprise [...]" (ISEFAC, [201-], On-line). alunos do BTS (Figura 4). Comentou, por fim, a respeito do desânimo que acomete muitos professores do estabelecimento, pois independente do que façam, os seus estudantes - sobretudo os das formações profissionais, em sua maioria advindos do entorno urbano - dificilmente conseguirão "quitter le quartier" ("deixar o bairro"). Laval et al. (2012) bem expressam a questão da guetorização escolar por meio de "'bolsões de dificuldade', 'instituições sensíveis'" (Cap.04, n.p., tradução nossa"11), que configuram, via escola, "poderosa alavanca para a reprodução social" (Cap.04, n.p., tradução nossa'2).

Representativo deste aspecto territorial de desigualdade educacional, reforçada por políticas neoliberais, no decorrer das incursões a campo um funcionário comentou em tom sarcástico "essa é a escola francesa da periferia...", negando o discurso de mix social, enquanto outro afirmou "os estudantes de Saint-Denis são os mais fracos".

\section{A empregabilidade como objetivo educacional}

Como analisado por Laval et. al. (2012), se "a empregabilidade é o princípio e o objetivo da normalização da escola, de sua organização e de sua pedagogia" (Apres., n.p., tradução nossa $\left.{ }^{13}\right)$, é necessário analisar a vinculação entre as mudanças no campo do trabalho e as mudanças no campo educacional, pois "é um novo sistema salarial que está sendo estabelecido e impõe seu padrão no mundo da educação: treinar indivíduos adaptáveis e personalidades fluidas" (Introd., n.p., tradução nossa ${ }^{14}$ ).

O Lycée Sugeré particularmente interessante por reproduzir, em uma mesma instituição, a segregação territorial e educacional, por meio do oferecimento de formações destinadas a diferentes públicos escolares, como comentado anteriormente, além de uma orientação profissionalizante do ensino secundário. Quanto às formações profissionais, o diretor do estabelecimento, em entrevista ${ }^{15}$, sublinhou que a abertura de turmas relaciona-se às demandas de qualificação ao trabalho da região - "a criação das formações profissionais não vem do ambiente social, mas de um ambiente econômico [...] (E1, tradução nossa) - e sublinhou os acordos de estágio estabelecidos, intermediados pela instituição escolar, sobretudo com empresas locais ou da região parisiense, configurando a modalidade de alternância, com formação na escola e na empresa.

O fenômeno da profissionalização da educação, debatido por Laval et al. (2012), expresso em um forte utilitarismo de formações direcionadas a postos de trabalho bastante específicos, foi observado, por exemplo, na grade horária de uma das formações do Lycée, orientada ao setor terciário: "Vendre; Conduite entretien vente; Négocier; Suivir prospection client; Accueil en face à face" ("Venda; Realizar entrevista de vendas; Negociar; Acompanhar prospecção de clientes; Recepção face a face"). Além disso, em visita à escola, observou-se cartazes de propaganda da região de Île-de-France de oferecimento de estágios (Figura 5), de salões de orientação profissional e também da faculdade ISEFAC Alternance, com proposta de ensino superior em alternância em suas mais de 6000 empresas parceiras. O mercado de trabalho é considerado como orientador da formação, vista como "trampolim para o mundo da empresa" (ISEFAC, [201-], On-line, tradução nossa ${ }^{16}$ ). 


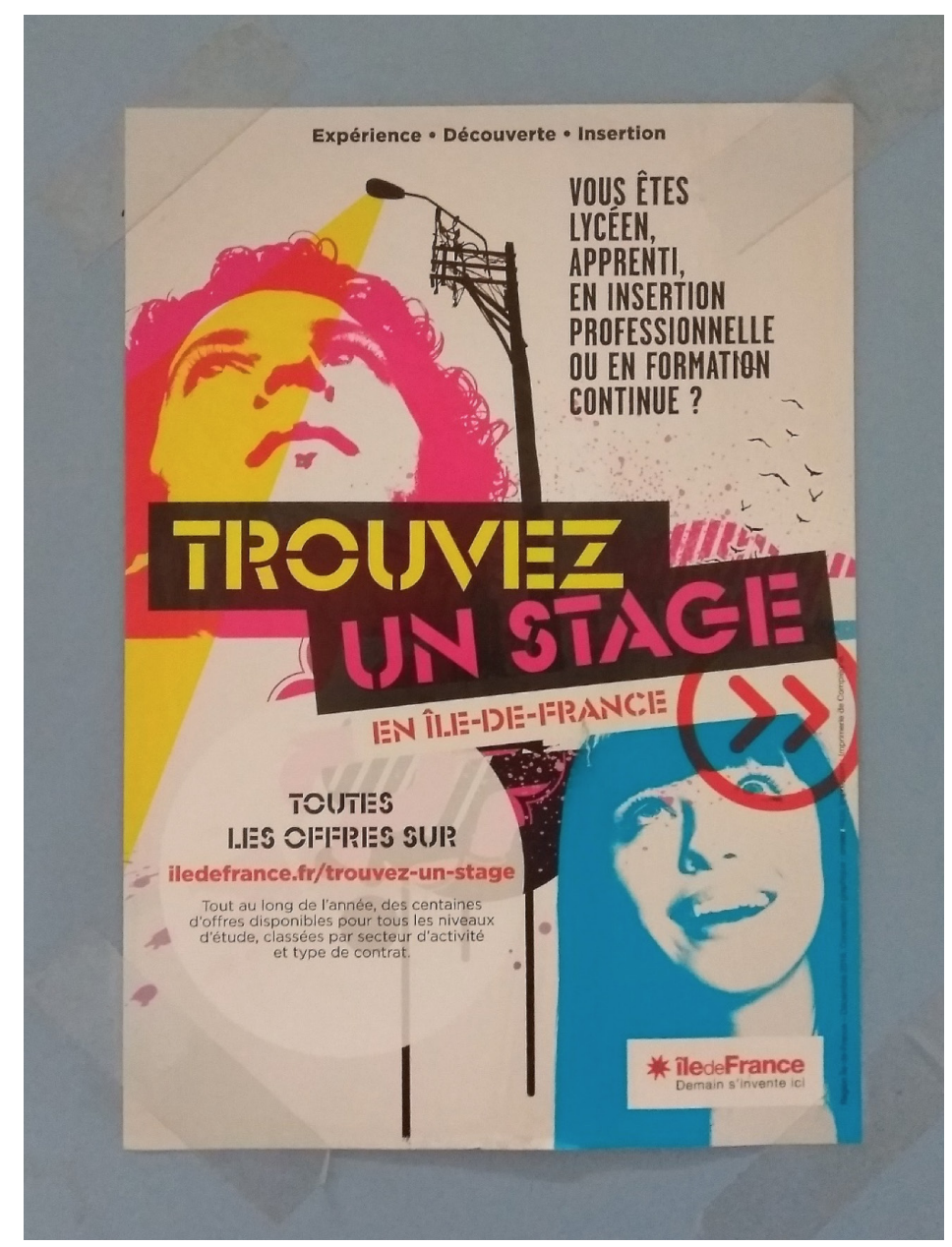

Figura 5: Cartaz de propaganda da Région île-de-France, afixado no Lycée Suger. Fonte: Autores (2019).

17 Entrevista realizada no dia 26 nov. 2019, na sala do entrevistado no Lycée.

18 "[...] l'élévation des niveaux de formation pour certaines catégories de jeunes, la limitation de la formation aux seuls horizonts de l'utilité productive directe pour beaucoup [...] " (LAVAL et al., 2012, Cap.03, n.p.)
Já os alunos da rede GRETA têm a oferta de formações pilotada pela demanda econômica local (FRANÇA, 2020, On-line), ou como expresso pelo coordenador da rede no estabelecimento ${ }^{17}$, orientam-se às "profissões identificadas como portadoras de emprego" (E2, tradução nossa). No caso das formações oferecidas no Lycée Suger, alinham-se aos grandes projetos urbanos em curso, como os vinculados aos Jogos Olímpicos.

Comum a todas as formações oferecidas no Lycée, destaca-se a orientação ao trabalho, seja o trabalho terciário de baixa qualificação e remuneração para os alunos das formações profissionais, o trabalho qualificado, de grande valorização e de grande mobilidade territorial aos alunos do BTS ou o trabalho orientado segundo a oferta de emprego local para os alunos de GRETA. Laval et al. (2012) debatem justamente o endereçamento diferenciado de formações a distintos públicos sociais - "a elevação dos níveis de formação para certas categorias de jovens, a limitação da formação aos horizontes de utilidade produtiva direta para muitos" (Cap.03, n.p., tradução nossa ${ }^{18}$ ) -, não obstante o cenário comum de precarização do trabalho e de orientação profissionalizante da escola. 
19 "[...] valeur d'échange sur le marché du travail [...]" (LAVAL et al., 2012, Introd., n.p.).
As formações escolares orientadas segundo a lógica das competências profissionais requeridas pelo universo do trabalho, reduzem a educação a um valor estritamente econômico, o seu "valor de troca no mercado de trabalho" (LAVAL et al., 2012, Introd., n.p., tradução nossa ${ }^{19}$ ), que abstrai, justamente, a dimensão humana e social intrínseca ao trabalho docente. De modo análogo à crise hospitalar que será debatida adiante, $\mathrm{o}$ alto desemprego entre jovens e adultos fundamenta um discurso de crise escolar, que demanda das escolas um vínculo mais próximo ao mundo econômico, por meio de estágios, da adoção da empresa como norma e de um modelo de "profissionalização".

Já em relação ao Parcoursup, os sindicatos de profissionais da educação têm se manifestado contra o processo de seleção operado por tal plataforma. "Éducation Sud" em publicação online de 26 de janeiro de 2020 destaca a concorrência, os critérios de seleção opacos por parte dos estabelecimentos e a discriminação territorial como algumas de suas consequências negativas (SUD ÉDUCATION, 2020, On-line). Durante conversa informal com funcionário que integra a equipe responsável pela segurança do Lycée, o Parcoursup foi citado como dispositivo de diferenciação territorial do acesso ao ensino superior. Comentando que se, na época de sua adolescência, ele, originário do 93, poderia pensar em ingressar em uma universidade de Paris, agora essa perspectiva estaria negada aos jovens alunos do Lycée, em sua maioria advindos do entorno próximo.

\section{Entre a escola e o hospital: a emergência no serviço público de saúde de Saint-Denis}

Na interface entre a escola e o hospital, os serviços de emergência surgem no espaço urbano desta periferia de Saint-Denis. Por mais de vinte anos, as desigualdades sociais e territoriais de acesso aos serviços públicos de saúde de qualidade na comuna de Saint-Denis vêm aumentando e se combinando com desertos médicos e taxas excessivas para a manutenção dos serviços do hospital (IZAMBERT, 2018). Diante do aumento da população jovem, mas também da população acima de 65 anos, com patologias como diabetes e doenças respiratórias crônicas, o hospital Delafontaine explicita um déficit de clínicos gerais. Os serviços de emergência, que são o único local de recepção possível para esses grupos, viram os seus números aumentarem. Como resultado, o departamento de emergência registra 55.000 visitas por ano, um número que aumenta de 6 a $8 \%$ a cada ano (BARDONNAUD; DESCOURAUX; HALLOT, 2019, On-line).

Ao mesmo tempo, as reformas hospitalares importam de modo crescente métodos gerenciais do mundo corporativo, pedindo aos cuidadores que façam mais com menos. Desde então, a abolição dos cargos de enfermagem aumentou, enquanto a escassez de médicos se estabeleceu (JUVEN; PIERRU; FANNY, 2019). Em julho de 2017, a Comissão de Assuntos Sociais do Senado publicou um relatório intitulado "Emergências hospitalares, espelhos de disfunções em nosso sistema de saúde" (FRANÇA, 2017, On-line), no qual foram relatadas as dificuldades organizacionais e estruturais encontradas por esses serviços (falta de leitos a jusante, aumento constante da atividade, uso da emergência para problemas sociais e médico-sociais, falta de atendimento médico, etc.). 
200 centro hospitalar Saint-Denis é um hospital público francês composto por dois locais: o hospital Delafontaine e o hospital Casanova. Com capacidade para pouco mais de 700 leitos e vagas (tendo o hospital Delafontaine 400 leitos), oferece serviços de internação e consulta em medicina, cirurgia, obstetrícia (M.C.O), geriatria e psiquiatria infantil. É classificado como SAU (Serviço de Recepção de Emergências) para emergências e possui serviço de atendimento móvel de emergência (SMUR) regulamentado pelo Samu 93. A área de influência do estabelecimento é de aproximadamente 250.000 a 300.000 habitantes (GHT, 2020, On-line).

21 "Nota técnica sobre o subfinanciamento dos custos adicionais de precariedade e suas consequências nas finanças do Centre Hospitalier de l'hôpital Delafontaine", Nota da Direção-geral do hospital à Agence régionale de santé (ARS), fevereiro de 2013.

Figura 6: Fachada do hospital Delafontaine, Saint-Denis.Fonte: Autores, 2019.

\section{A recepção da emergência do hospital Delafontaine}

A partir da observação direta na recepção do Centro Hospitalar Saint-Denis ${ }^{20}$ (Figura 6) sobressaíram como principais atores os cuidadores, técnicos e enfermeiros, que acolhem esses pacientes na recepção da emergência, uma espécie de sala de passos perdidos, onde os pacientes aguardam serem chamados em uma modalidade que se aproxima a um serviço de balcão. Chama a atenção o tratamento diferenciado, com distintos planos de saúde para cobertura das despesas hospitalares, entre os franceses e estrangeiros em situação legal (Coverture Maladie Universelle-complémentaire-CMU-C) e os estrangeiros em situação irregular (l'Aide médicale d'État-AME) (COGNET, 2012; IZAMBERT, 2016; MOREL, 2016).

Segundo Caroline Izambert (2018), das quase 30.000 estadias no Hospital Delafontaine em 2012, mais de 2.500 (o que representa mais de 11\%) foram financiadas pelo Aide Médicale de l'Etat(AME) e, portanto, dizem respeito a pessoas em situação irregular21. Para dar uma ordem de grandeza, lembremos que as estimativas do número de pessoas em situação irregular em território francês é de cerca de 400.000, ou seja, 0,6\% da população.

Aberto 7 dias por semana e acessível 24 horas por dia, as Emergências são local de confluência de inúmeras demandas, que acabam por congestionar este setor crítico de atenção médica. Os serviços de emergência têm a missão inicial de atender continuamente às necessidades de cuidados imediatos, mas também devem enfrentar solicitações não programadas de cuidados, priorizadas de acordo com a gravidade da condição do paciente. Os pacientes, depois de terem passado pela recepção de emergência, que atua como local de triagem, são distribuídos entre diferentes zonas de acordo com a gravidade de sua condição: cuidados de baixa complexidade (gessos e suturas); alta complexidade como os serviços de reanimação; o setor de média complexidade, onde os pacientes geralmente ficam em observação.

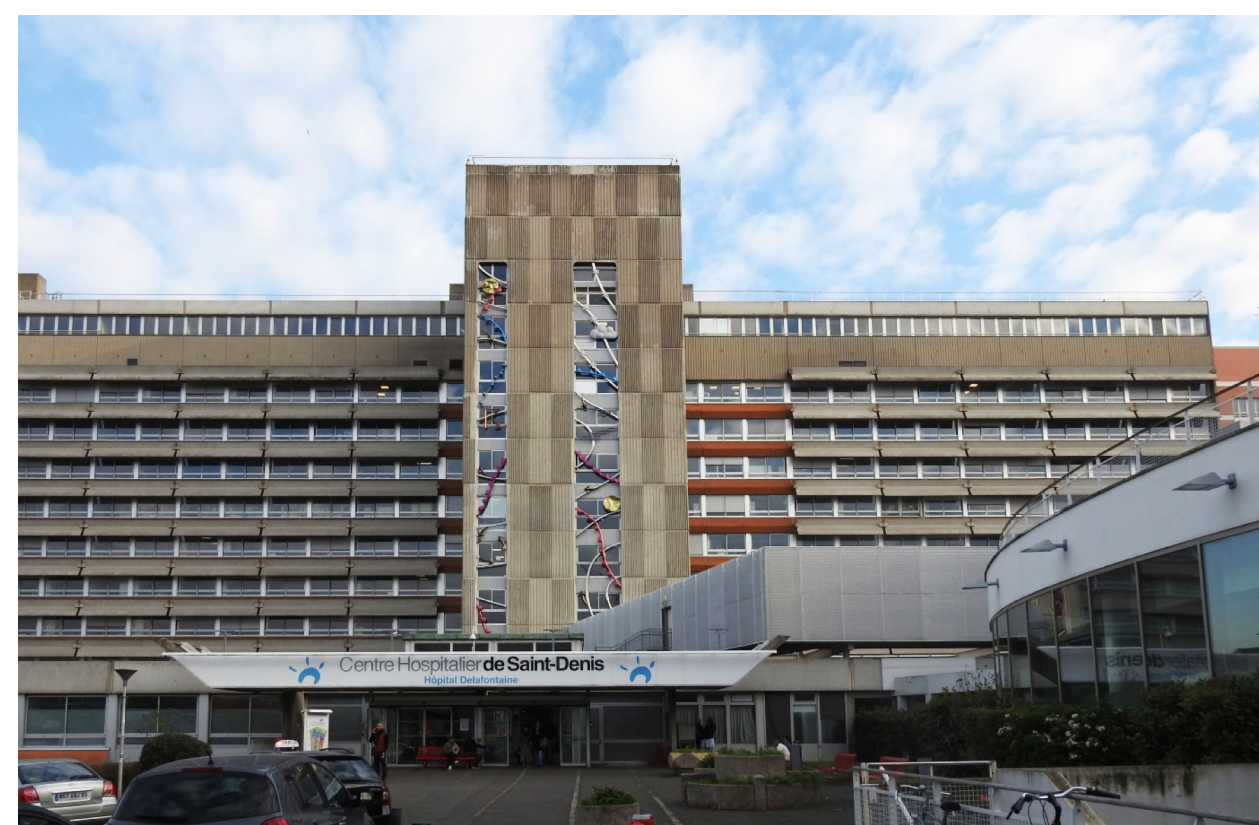


$22 \mathrm{DE}$ refere-se ao diploma de auxiliar de enfermagem reconhecido pelo Estado.
230 sistema "hospital sob tensão" ou "hospital sob pressão" (BELORGEY, 2010), consiste em desviar ambulâncias para outros hospitais porque o hospital em questão atingiu sua taxa máxima de ocupação. É um sistema de prevenção e gerenciamento de crises implantado quando o serviço fica muito congestionado.
Essa distribuição do cuidado em vários setores implica uma especialização de determinadas posições com uma diversificação das tarefas a serem desempenhadas pelos cuidadores (VASSY, 2001), os quais devem então alternar entre esses vários setores. Assim, um dos enfermeiros entrevistados (E3), 42 anos de idade, estará um dia na sala de cirurgia, no dia seguinte na recepção e na semana seguinte no atendimento ambulatorial. Como afirmam os profissionais, o objetivo dessa mudança é promover a versatilidade dos trabalhadores e evitar rotinas. Constantemente acostumado a se adaptar a um ritmo irregular de trabalho específico para o setor de emergência e atendimento não programado, o pessoal da Emergência realiza muitas mudanças de tarefas (HUGHES, 1997).

\section{ASA: reconfigurações neoliberais no trabalho de emergência}

Em 2019, para combater o congestionamento em seu departamento de emergência, a administração do hospital, no entanto, decidiu criar a posição de "cuidadora de recepção" (Aide-Soignante d'Accueil)(ASA) (VASSY, 2001). Tal posição foi oferecida à técnica de enfermagem com a qual conversou-se (E4), 56 anos, ao final de sua carreira. Seu trabalho é informar as famílias de pacientes sobre o progresso dos cuidados de seus entes queridos. É uma jornada de trabalho com horários flexíveis: das $13 \mathrm{~h}$ às $21 \mathrm{~h}$. E4 afirmou que não fará mais o seu trabalho de cuidadora, seu trabalho agora é apenas atender o telefone, acompanhar o progresso dos pacientes através de um software em seu computador e conversar com as famílias: "Por um lado, é bom porque estou quieta, fico sentada quase o dia todo, mas, por outro lado, bem, não é o meu trabalho! Na verdade, faço trabalho de secretariado. De repente, eles poderiam ter contratado uma secretária! Era inútil fazer um $D^{22}$ para isso!" (E4, tradução nossa). A interlocutora não esconde o fato de que ela vê esse cargo pós-carreira como um desdobramento, desde que ele a coloque imprensada entre cuidadores e famílias. Essa nova organização certamente ajuda a evitar congestionamentos nos corredores e permite que os cuidadores do serviço façam seu trabalho com pouco mais de tranquilidade, mas ao mesmo tempo concentra todo o gerenciamento dos problemas em uma única pessoa que depois se encontra sozinha e vulnerável ao nervosismo das famílias.

Em novembro de 2019, momento no qual os profissionais de saúde já estavam em greve, uma assembleia foi convocada no departamento de emergência de Saint-Denis, após o esgotamento dos cuidadores diante de picos de atendimento sem precedentes neste serviço. A urgência de Saint-Denis alcançou a marca de 200 passagens diárias em vez de 150 habituais porque os hospitais vizinhos continuavam em "tensão" 23 , as ambulâncias acabavam sendo enviadas de volta a Saint-Denise as epidemias de inverno (gripe, doenças gastrointestinais etc.) levavam muitos pacientes à sala de emergência.

A greve de 2019 obteve uma forte mobilização e adesão (90\% dos profissionais de emer-gência declararam greve) e perdurou por muito tempo através da prática da "greve perlée": uma hora por dia, os profissionais de saúde exibiam uma etiqueta grudada grosseiramente nas costas: "Estou em greve, mas eu cuido" (" Je suis en grève mais je soigne »).

A lógica gerencial em curso propõe uma posição adicional às enfermeiras diurnas como é o caso de outra interlocutora com a qual dialogou-se (E5). Esta posição, chamada 
24 IDE significa Infermier Diplomê d'Etat (Enfermeira do Estado). A profissão de IDE também pode cobrir a de Cuidador. "abelha", consiste em apoiar os cuidadores, onde for necessário, entre as 11 e as 20 horas durante o período de verão: "Assim como uma abelha essa enfermeira deve estar lá às vezes, sazonalmente, finalmente quando há necessidade. Por exemplo, fortalecer a recepção quando necessário" (E5, tradução nossa). Portanto, é uma posição temporária destinada a otimizar o fluxo de pacientes e delegar determinadas tarefas, anteriormente realizadas pelos enfermeiros de acolhimento e orientação. "A abelha" deve, por exemplo: atender o telefone para informar as famílias. Para isso, o espaço é reorganizado: "Instalamos uma tela em frente aos banheiros dos funcionários (já que eles não podiam ir lá com frequência) e decretamos que será um local de atendimento" (E5, tradução nossa).

Na prática, a interlocutora terá que substituir o gerente enquanto a vaga não for preenchida: "Veja, eu estava de licença, volto para casa e os colegas me dizem que é você quem substitui [o gerente do setor], e, sem pedir a minha opinião, apesar de tudo" (E5, tradução nossa). O que poderia ter sido vivenciado como uma promoção não é bem visto pela enfermeira:

Eu não quero fazer o trabalho! Sim, ok, eu sei planejar, mas se eu passei no IDE 24, sou eu mesma uma enfermeira, para não ficar sobrecarregada com a papelada! Além disso, imagine o que significa fazer os horários da equipe quando você faz parte da equipe [...]. E então, como eu tenho que fazer o trabalho, com um salário IDE? Além disso, por falar em salário, nem vou poder trabalhar à noite, de repente vou ganhar muito menos!. (E5, tradução nossa)

Devido ao seu tamanho, as Emergências, como interface entre a sociedade e o hospital, são um reflexo das "disfunções no sistema de saúde" (FRANÇA, 2017, On-line). O sistema regulatório implementado para reduzir esse congestionamento, no entanto, tende a acentuar as disfunções. Por um lado, fechar as portas às famílias dos pacientes é uma fonte de conflito e coloca os ASAs em uma posição de insegurança. Por outro lado, a maneira pela qual a gerência hospitalar lida com o fluxo dos usuários para contê-lo tende a criar uma situação desconfortável para os pacientes, suas famílias e para os cuidadores. A ASA e a enfermeira "abelha", apesar de pertencerem a diferentes grupos profissionais, têm alguns pontos de semelhança, principalmente por ocupar uma posição cujo trabalho atua em uma lacuna (SAINSAULIEU, 2007). Nos dois casos, trata-se mais de implementar medidas paliativas de baixo custo do que de resolver a substância do problema para o qual a gerência local ou os atores profissionais não têm necessariamente a solução. Desregula-se o acesso, responsabilizando os cuidadores em vários setores da administração dos serviços de saúde, condicionando, ao mesmo tempo, a gestão de baixo custo do hospital, como uma empresa em nome da eficácia e da flexibilidade do setor privado. O protesto no jaleco branco da interlocutora E5 e as frases expressas em cartazes, durante as manifestações contra a Reforma da Previdência do governo de Emmanuel Macron, denunciam a "demolição da ideia de serviço público" enunciada por Bourdieu (1993, p. 340): "Maternité en grève, mais je soigne. La couche est pleine" ("A maternidade está em greve, mas eu cuido. A fralda está cheia") (Figura 7). "Laissez nous soigner dignement" ("Deixem-nos cuidar com dignidade") (Figura 9); "Soignants low cost, non!" ("Cuidadores baixo custo, não!) (Figura 8). 


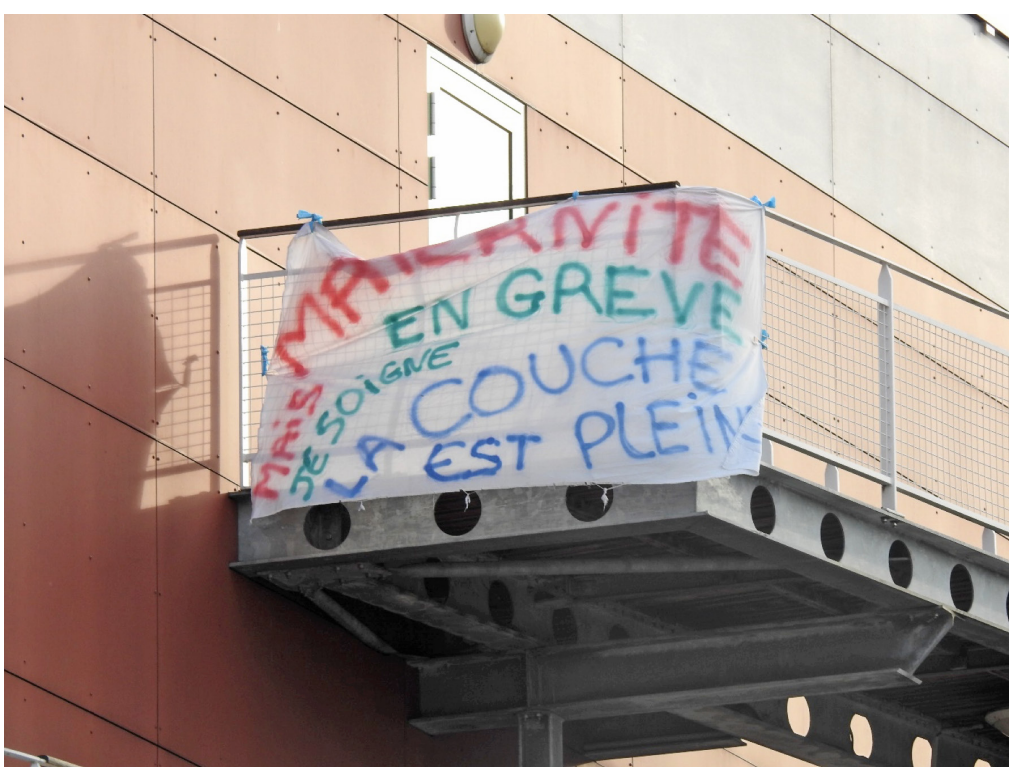

Figura 7: Faixa na entrada do Centro Hospitalar Saint-Denis em 20 nov. 2019. Fonte: Autores, 2019.

Figura 8: Profissional do Centro Hospitalar Saint Denis na manifestação contra a Reforma da Previdência, dez. 2019. Fonte: Autores, 2019.

Figura 9: Cartaz durante a manifestação contra a Reforma da Previdência em Place de la République, Paris, 16 dez. 2019. Fonte: Autores, 2019.
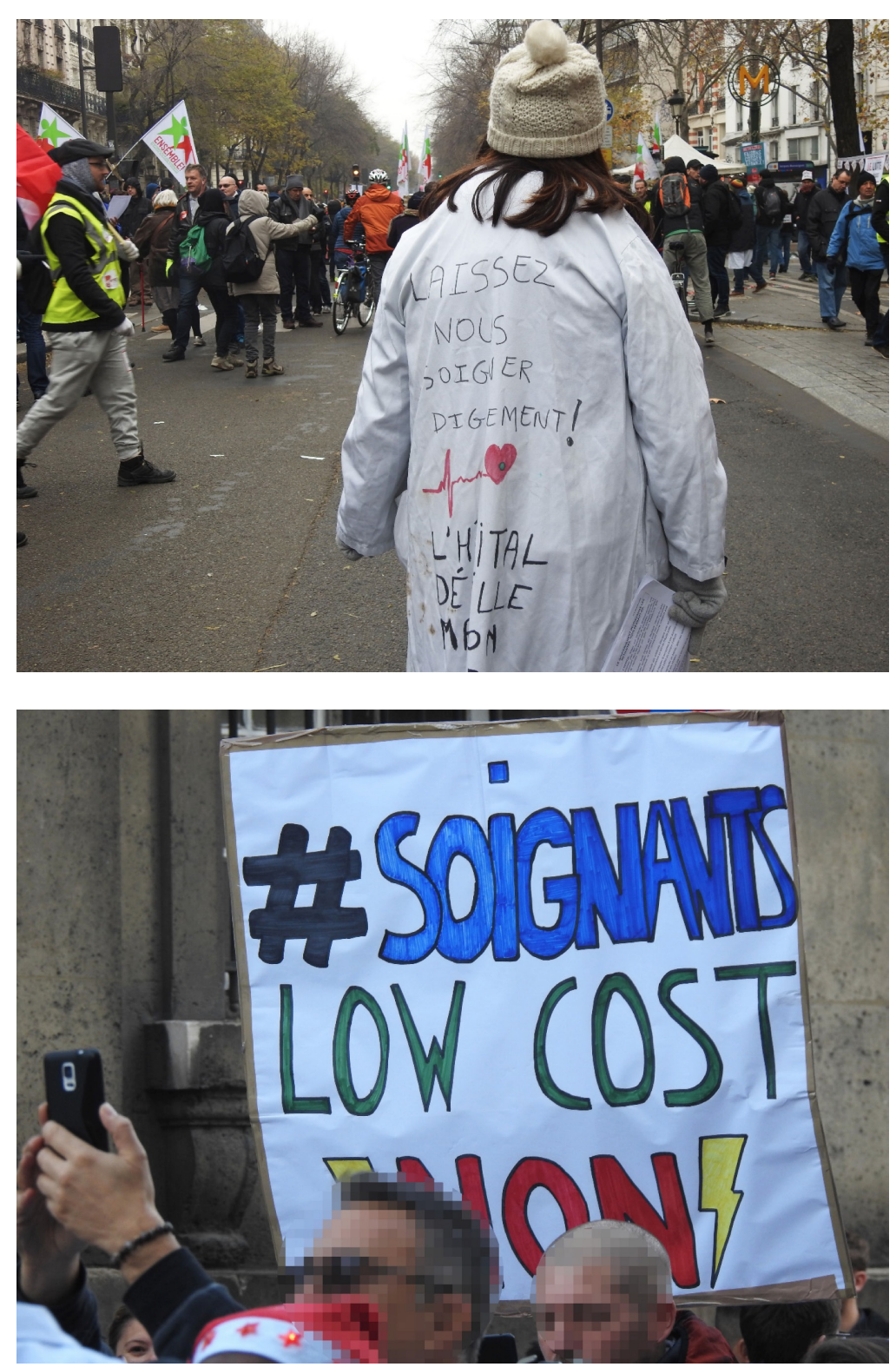
25 "[...] les mêmes recettes du 'management de la performance" (LAVAL et al., 2012, Cap.01, n.p.).
26 "[...] faire fonctionner le système éducatif directement, sans distance et sans médiation, comme une entreprise productrice de 'capital humain' " (LAVAL et al., 2012, Post., n.p.).

27 "[...] la stratégie des 'petits pas' irréversibles" (LAVAL et al., 2012, Cap.05, n.p.).

\section{Considerações finais}

A análise das transformações nas políticas sociais em Saint-Denis suscita a reflexão a respeito das periferias metropolitanas como locais privilegiados de inserção de novas lógicas nos serviços públicos relativos aos direitos sociais. O esgotamento dos profissionais de saúde face às crescentes medidas de exploração no trabalho visibilizam relações de poder que beiram a insustentabilidade e têm nos territórios de maiores vulnerabilidades sociais expressões da mais alta perversidade, avessa a qualquer sentido de saúde pública. Já as políticas de profissionalização na educação têm nestes mesmos territórios periféricos possibilidades de experimentação de novas modalidades de penetração de lógicas gerenciais e privatistas, como por exemplo, via plataforma Parcoursup.

As transformações do trabalho e das formas de emprego dos profissionais de saúde (especificamente técnicos de enfermagem e enfermeiros), alterando as linhas de produção no chão de fábrica do hospital (BELORGEY, 2012), são um campo etnográfico privilegiado de observação de semelhantes processos de transformação, desmantelamento e privatização de setores inteiros do Estado. Conforme expresso por Laval et al. (2012), é necessário compreender o papel central do Estado na realização das transformações de caráter neoliberal em curso não apenas no campo da educação, mas em todos os campos de outros direitos sociais, generalizando "as mesmas receitas de 'gerenciamento de performance'" (Cap.01, n.p., tradução nossa ${ }^{25}$ ), pautadas em avaliação, recompensas individualizadas, competição, transformação de direitos em serviços prestados a clientes, quantificação dos objetivos e orientação pela demanda. Afinal, esta "lógica" de gestão empresarial aplicada à gestão pública (conceituada por Christopher Hood em 1991 como "New Public Management"), constituiu um modelo de reforma do Estado difundida e aplicada internacionalmente, nos vários campos de atuação estatal.

A hipótese de partida era que as manifestações neoliberais nesses dois campos de pesquisa, educação e saúde, se articulavam a mudanças no campo do trabalho, por meio de medidas gerenciais, ainda que de formas distintas em cada campo. A centralidade do trabalho para análise das transformações em políticas de educação e saúde é possível devido à noção de capital humano, que reorienta o sentido dos trabalhadores da saúde com metas de performance e lucratividade desse serviço de gestão da vida. Orienta igualmente a educação de modo a "fazer funcionar o sistema educativo diretamente, sem distância e sem mediação, como uma empresa produtora de 'capital humano'" (LAVAL et al., 2012, Post., n.p., tradução nossa ${ }^{26}$ ), para enformamento do indivíduo ao trabalho flexível na contemporaneidade.

Por fim, se o presente artigo abordou processos em curso em que o avanço neoliberal se dá em uma arena de disputas, é importante compreender a lógica geral que reorienta a dimensão do trabalho em ambos os campos, educação e saúde: "a estratégia de 'pequenos passos' irreversíveis" (LAVAL et al., 2012, Cap.05, n.p., tradução nossa27).

\section{Agradecimentos}

À Coordenação de Aperfeiçoamento de Pessoal de Nível Superior - Brasil (CAPES), pelo apoio à pesquisa de Mestrado de Miranda Zamberlan Nedel (Código de Financiamento 001). 


\section{Referências bibliográficas}

BARDONNAUD, Philippe, DESCOURAUX, Vanessa, HALLOT, Géraldine Hallot. Les urgences à bout de souffle. France Inter, França, 29 set. 2019. Disponível em: <https://www. franceinter.fr/emissions/interception/interception-29-septembre-2019>. Acesso em 20 fev. 2019.

BEHAR, Daniel., LOISEL, Manon., RIO, Nicolas. La fin du 9-3? La Seine-Saint-Denis entre représentations et métropolisations. In: Le 9-3, un territoire de la nation. Hérodote revue de géographie et de géopolitique. n¹62, 2016.

BELORGEY, Nicolas., L'hôpital sous pression. Enquête sur le " nouveau management public », La découverte, Paris, 2010.

De l'hôpital à l'état : le regard etnographique au chevet de l'action publique. Presses de Sciences Po I «Gouvernement et action publique » 2012 I n 2 I pp. 9 à 40. Diponível em: <https://www.cairn.info/revue-gouvernement-et-action-publique-2012-2-page-9. htm>. Acesso em 10 dez. 2019

BOURDIEU, Pierre. La misère du monde. Éditions du Seuil, 1993.

COGNET, Margueritte. L'hôpital, un ordre négocié à l'aune des origines. « Français » et « Africains » en traitement pour un VIH-sida », Migrations santé, n 144-145, p. 79-110, 2012. Disponível em : https://documentation.ehesp.fr/index.php?|vl=author_see\&id=119561. Acesso em 25 jan. 2020.

COLLECTIF INTER-HÔPITAUX. FRANÇA. Disponível em https://www.collectif-inter-hopitaux. org/. Acesso em 17 fev. 2020.

COLLECTIF INTER-URGENCE. FRANÇA. Disponível em <https://www.interurgences.fr/>. Acesso em 17 fev. 2020.

DARDOT, Pierre; LAVAL, Christian. A nova razão do mundo: ensaio sobre a sociedade neoliberal. São Paulo: Boitempo, 2016.

FOUCAULT, Michel. Nascimento da Biopolítica: curso dado no Collège de France (1978-1979). São Paulo: Martins Fontes, 2008.

FRANÇA. Les urgences hospitalières, miroir des dysfonctionnements de notre système de santé. Senado. Disponível em: <http://www.senat.fr/rap/r16-685/r16-6851.html>. Acesso em 05 dez. 2019.

Ministère de l'Éducation Nationale, de la Jeunesse et des Sports. Les GRETA. 2020. Disponível em: https://www.education.gouv.fr/les-greta-2957. Acesso em: 05 set. 2020.

GROUPEMENT HOSPITALIER DE TERRITOIRE (GHT). Le centre hospitalier de Saint-Denis. França, GHT. Disponível em: <http://www.ch-stdenis.fr/le-ch-de-saint-denis/presentation,27,73. html>. Acesso em 20 fev. 2020.

HUGHES Everett. Le regard sociologique, Paris, Presses de I'EHESS, 1997

INSEE. Dossier complet Commune de Saint-Denis (93066). 09 dez. 2020. Disponível em: <https://www.insee.fr/fr/statistiques/2011101?geo=COM-93066>. Acesso em: 18 dez. 2020.

ISEFAC ALTERNANCE. Pourquoi ISEFAC en alternance. [201-]. Disponível em: <https://www. isefac-alternance.fr/>. Acesso em: 24 fev. 2020.

IZAMBERT, Caroline. Logiques de tri et discirminations à I'hôpital public : vers une nouvelle morale hospitalière ? Revue Agone n 58, p. 89-104, 2016. Disponível em: <https://www. cairn.info/revue-agone-2016-1-page-89.htm>. Acesso em 05 set. 2020.

Soigner les étrangers ? L'État e les associations pour la couverture maladie des pauvres et des étrangers en France des années 1980 à nos jours. Thèse de Doctorat. Université de recherche Paris Sciences et Lettres. 2018. 
HARVEY, David. A produção capitalista do espaço. São Paulo: Annablume, 2005.

JUVEN Pierre.-André., PIERRU Frédéric., VINCENT Fanny. La casse du siècle: à propos des réformes de I'hôpital public, Paris, Raison d'agir, 2019

LAVAL, Christian et al. La nouvelle école capitaliste. Paris: La Découverte, 2012. E-book. n.p.

LAVAL, Christian; DARDOT, Pierre. A prova política da pandemia. In: RENZO, Artur (ed.) Blog da boitempo. São Paulo, 26 mar. 2020. Disponível em: <https://blogdaboitempo.com. br/2020/03/26/dardot-e-laval-a-prova-politica-da-pandemia/>. Acesso em: 21 maio 2020.

LINTERNAUTE. Seine-Saint-Denis (département 93). 2017. Disponível em: <http://www.linternaute.com/ville/seine-saint-denis/departement-93>. Acesso em: 23 fev. 2020.

LYCÉE SUGER (Région Île-de-France). [201-]. Disponível em: <http://suger.fr/>. Acesso em: 21 jun. 2020.

MÉTROPOLE GRAND PARIS. Inventons la Métropole du Grand Paris: la vidéo de lancement. 11 out. 2016. Disponível em: <https://www.youtube.com/watch?v=8jDo18ZBhgw>. Acesso em: 31 ago. 2020.

MOREL, Sylvie. La fabrique médicale des inégalités sociales dans I'accès aux soins d'urgence. Ethnographie comparée de deux services d'urgence public et privé. Revue Agone 2016/1 ( $n^{\circ}$ 58), p. 73-88. Disponível em: https://www.cairn.info/revue-agone-2016-1-page-73. htm. Acesso em 29 nov. 2019.

PERRIER, Nathalie. Au lycée Suger, la tension monte après de nouvelles violences. Le Parisien, Saint-Ouen, 23 set. 2016. Disponível em: <https://www.leparisien.fr/seine-saint-denis-93/ au-lycee-suger-la-tension-monte-apres-de-nouvelles-violences-23-09-2016-6143101.php>. Acesso em: 30 ago. 2020.

SAINT-DENIS: 55 personnes interpellées après des violences au lycée Suger. Franceinfo, Paris, 08 mar. 2017. Disponível em: <https://www. francetvinfo.fr/societe/education/saint-denis-55-personnes-interpellees-apres-des-violences-au-lycee-suger_2085809.html>. Acesso em: 21 jun. 2020.

SEINE-SAINT-DENIS TOURISME (Département). Du bidonville au logement décent: la Cité des Francs-Moisins à Saint-Denis. [200-]. Disponível em: <https://www.tourisme93.com/document.php?pagendx=963>. Acesso em: 20 jun. 2020.

SCHWARZ, Roberto. Ao vencedor as batatas. São Paulo, Duas Cidades, 1992.

SUD ÉDUCATION. Parcoursup: an III. Communiqué de la fédération SUD éducation. 26 jan. 2020. Disponível em: <https://www.sudeducation.org/Parcoursup-an-III.html>. Acesso em: 17 de fev. 2020.

SAINSAULIEU, Ivan. L'hôpital et ses acteurs: Appartenances et égalité. Paris, Belin, 2007.

VASSY, Carine. Categorisation and micro-rationing: access to care in a French emergency department, Sociology of Health and IIIness, Vol. 23, n5, p. 615-632, 2001. Disponível em: <https://www.hal.inserm.fr/hal-01275608/>. Acesso em: 15 mar. 2020.

VAN ZANTEN, Agnès. L'école de la périphérie. Paris: PUF, 2001. E-book. n.p. 